\title{
Teaching medical ethics
}

\section{Review of the teaching of medical ethics in London medical schools}

\author{
S J Burling, J S P Lumley, L S L McCarthy, J A Mytton, J A Nolan, P Sissou, D G Williams, L J Wright \\ St Bartholomew's Hospital, London
}

\section{Authors' abstract}

The study examined the influence of the Pond Report on the teaching of medical ethics in the London medical schools. A questionnaire was given to both medical students and college officers.

All medical colleges reported that ethics was included in the curriculum. However, from students' replies, it seems that attendance of optional courses is low and that not all current final year medical students have had any formal teaching in medical ethics. Stronger guidelines are necessary to ensure appropriate ethical training in London medical schools.

\section{Introduction}

Traditionally medical ethics has received little attention in the medical curriculum. It has often been assumed that ethically 'correct' decisions can be made in individual cases purely on the basis of a scientific training.

Only the more recently established medical schools (Nottingham (1) and Southampton (2)) or those with a strong religious bias (King's College, London) have well-integrated and comprehensive courses in medical ethics. Otherwise, any formal teaching that has been included has been in forensic medicine, psychiatry or in the context of voluntary, extracurricular settings, such as the regional Student Medical Groups associated with the Institute of Medical Ethics. Informal teaching does take place during clinical attachments.

In 1984 the institute, with encouragement from the General Medical Council, convened a working party to study the teaching of medical ethics in British medical schools. The outcome was published in 1987 as the Pond Report (3). The brief given to the working party was: 'To express and illustrate its understanding of medical ethics teaching and to identify existing teaching arrangements ... to discuss alternative teaching options, academic standards and possible pitfalls, and to make recommendations'.

\section{Key words}

Medical ethics; Pond Report; medical school; medical school curriculum.
The initial considerations of the working party concluded that 'at present, the teaching of medical ethics will be best encouraged by encouraging local initiatives'. The working party hoped that the experience of these initiatives over the next five years would provide an opportunity for reassessment of alternative teaching options. We have reassessed the current state of teaching on medical ethics in the London medical schools to examine the degree to which the Pond Report has been implemented.

\section{Aim}

1. To determine the extent and format of ethics teaching in the London medical schools.

\section{Questionnaire (table 1)}

Medical ethics - A student's guide

1. Is there any medical ethics taught at your medical school?

2. When in the curriculum is it taught?

3. How much teaching is there? (hours)

4. What is the format of the teaching?
a) Lectures
b) Seminars
c) Discussion groups
d) Other: please give details

5. Who teaches it?
a) Pre-clinical staff (specify)
b) Clinical staff
c) Non-medical staff/guest lecturer
d) Others: please give details.

6. Is the teaching optional?

7. Is it examined? If so, at what level?

8. What future changes are planned in the teaching of medical ethics? 


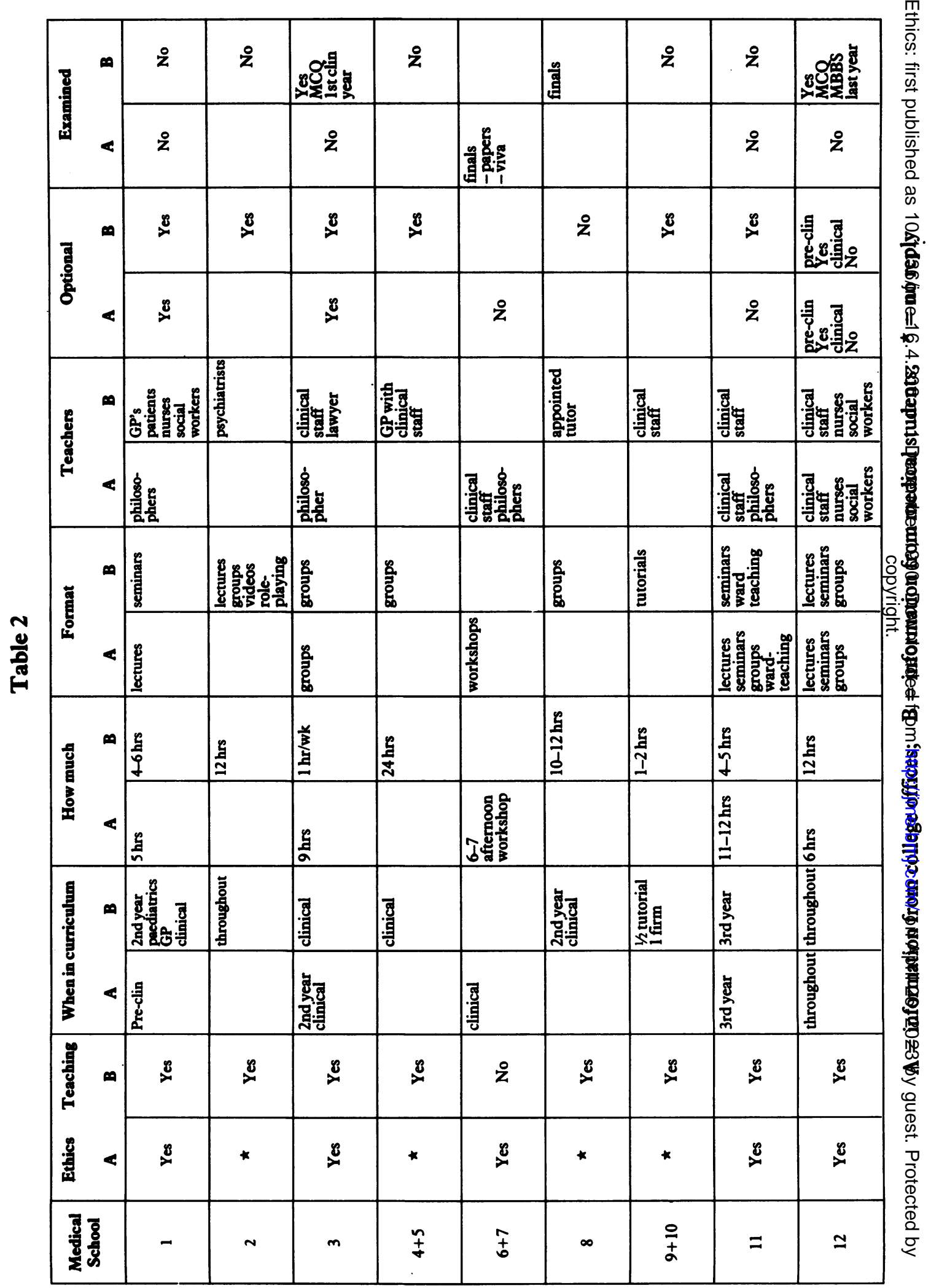


2. To compare the reported amount of ethical teaching by students and medical college offices.

3. To determine to what degree the recommendations of the Pond Report have been accepted and instituted by the London medical schools.

\section{Methods}

The questionnaire (table 1) was presented, either verbally or in writing, to representatives of medical college offices and students of all London medical schools. Additional information was sought from student nurses in one school. The study was carried out in 1989.

\section{Results}

1. Is there any medical ethics taught at your medical school?

All responding medical schools claimed to teach a course in medical ethics.

\section{When is it taught?}

One medical school taught it only in the pre-clinical years, and throughout the undergraduate course. The remainder taught it exclusively in the clinical curriculum.

\section{How much teaching is there?}

This varied from two hours in one medical school, to 24 hours in another: the commonest response being 12 hours.

\section{What is the format of the teaching?}

Lectures, seminars and discussion groups were common. One college emphasised ward teaching and another used videos and role playing.

\section{Who teaches it?}

The teachers included clinical staff, general practitioners, nurses, social workers and patients. Four colleges reported employing a philosopher, but this was only confirmed at one place by the students of one college. A lawyer is involved at another college and one medical school had appointed tutors for groups of students.

\section{Is the teaching optional?}

Attendance was optional in all but two colleges.

\section{Is it examined?}

Medical ethics has been examined in two medical schools: in one it formed part of a multiple-choice question paper in the first clinical year; in the other, an essay question was included in the final MBBS. Another medical school intends to examine medical ethics in final MBBS, but has not done so as yet.

\section{Comparison of student and medical office responses}

Replies were received from students at each of the London medical colleges. These showed that ethics was being taught in all but two schools. In one of these two schools, a recent curiculum change has been implemented to include ethics.

In all but one college students felt they were receiving the ethics curriculum claimed to have been implemented by official sources.

From the student replies it was evident that attendance at courses which were optional was poor.

Despite the fact that many college offices had extensive plans for expanding the medical ethics curriculum, little of this had been conveyed to the student bodies.

\section{Discussion}

All of the responding London medical schools are currently teaching medical ethics to a varying extent. Two of the schools are in the process of implementing a new course. There is a great deal of variation in the amount of teaching (2-24 hours), its format and the point in the undergraduate course when it occurs.

A multidisciplinary approach is favoured, allowing a greater range of viewpoints to be put forward. With the teaching being optional and not examined in most colleges, only those students interested in this field are likely to attend. This means a large number of students will still be lacking any formal training in ethical principles at the time of qualification.

Communication with student nurses and published recommendations on the ethics training of social workers (4), physiotherapists (5) and dieticians (6), reveals that these professions receive a more structured course in ethics than do medical students.

\section{Review of Pond Report and suggested improvements}

Since the publication of the Pond Report in 1987, changes have occurred in most London medical school curricula such that a medical ethics course is now taught.

It was considered by this group that the recommendations outlined in the Pond Report were helpful. However, recommendation number 10, that 'Medical ethics teaching within the curriculum should not be regarded as superseding the unique contribution of the Student Medical Groups', would suggest that curriculum teaching is considered to be less important than these voluntary sessions.

Indeed, the 'London Medical Group' has now been disbanded. Previously, this provided a forum for interested medical and nursing students to discuss ethical issues arising from the practice of medicine. The loss of this group to London medical students, largely due to financial restrictions, strengthens the need for a set ethics syllabus in the curriculum. Now, even interested students are unable to confront these issues in a group setting (though certain London medical schools have developed their local versions of the London Medical Group).

The Pond Report, states that it 'does not wish to recommend a specific syllabus for medical ethics 
teaching'. However, we feel that stronger guidelines should be given regarding the content of a medical ethics syllabus. The adoption of these guidelines into the curriculum will be left to each medical school.

The inclusion of specific discussion topics would draw the attention of students to these issues. Agreement of these topics by all colleges would encourage them to be included in qualification examinations. It is encouraging that King's College, London and two other combined schools have developed similar curricula, based on the work of Dr Len Doyal (7). We agree with his emphasis and recommend the following proposals:

\section{COURSE CONTENT}

A course should begin in the second pre-clinical year and run throughout the clinical curriculum. The preclinical syllabus should be an introduction to medical ethics consisting of 8-10 sessions covering:

1) General principles of ethics.

2) Developmental problems, for example, genetic engineering, embryo experimentation, abortion and definition of life.

3) Resource allocation.

4) Clinical research.

5) Community issues, for example provision of care for elderly and mentally handicapped, prevention versus cure.

Teaching during clinical attachments should include the presentation of ethical problems during academic half-days in each specialty, together with an additional eight sessions on specific topics such as, patient autonomy, consent, communication, confidentiality, legal requirements and priorities.

The current practice of full discussion of practical and ethical dilemmas, that students and doctors encounter, should continue and supplement the above proposals.

\section{METHOD OF TEACHING}

This should be in the format of lectures combined with group discussions of real or model case presentations.

\section{ASSESSMENT}

The format of assessment should be left to individual medical colleges, but we concur with the recommendations of the Pond Report that examination questions on ethical issures should be included in the final MBBS examination. This would verify that students are able to think critically and logically about ethical issues and are able to defend these beliefs against counterarguments.

\section{Comment}

The ability of a doctor or health professional to make a rational decision in the face of an ethical dilemma depends on a hierarchial system of moral deliberation. At the base of this alogrithmic system are the 'ethical theories' which ultimately attempt to define, explain and justify human morals. These theories determine 计 framework of fundamental principles which, in turn define the rules and precedents which are applied to: specific actions and judgements.

One of the problems in ethics is to develop $\vec{a}$ universal set of principles which will function for alE humanity and not just certain societies. It is widelye believed that the fundamental principles in medicine are beneficence (8), non-maleficence (8), justice (9) and respect for the individual. The last of these? encompassing the concepts of autonomy (10) and confidentiality (11). It is possible these principles are fundamental to all society, and not confined to the practice of health care.

Medical education should endeavour to teach somed of the philosophy and reasoning behind theses concepts. The little teaching which exists at present is entirely utilitarian and few medical students have anyo understanding of the theoretical concepts involved $\circ$ Consequently, they are not in a position to make informed rational judgements. The teaching of ethics provides an ideal opportunity for analysis of personap views and development of rational argument practice that is not encouraged in traditional medicas teaching.

I S P Lumley MS FRCS is Professor of Vascular Surgerye at St Bartholomew's Hospital, London where S F Burli L S L McCarthy BSc, $\mathcal{f}$ A Mytton, $\mathcal{F}$ A Nolan BSc $\leq$ P Sissou $B S c, D G$ Williams and $L \mathcal{F}$ Wright $B S c$ were filif year medical students. They have all now qualified.

\section{References}

(1) Jones J S P, Metcalf D H H. The teaching of medicat ethics in the Nottingham Medical School. Fournal of medical ethics 1976; 2: 83-86.

(2) Dennis K J, Hall M R P. The teaching of medical ethic at Southampton University Medical School. Fournal of medical ethics 1977; 3: 183-185.

(3) Boyd, $\mathrm{K} \mathrm{M}$ ed. Report of a working party on the teaching of medical ethics - Chairman Sir Desmonฐ Pond: The Pond Report. London: IME Publications 1987.

(4) British Association of Social Workers. Code of ethics fo social workers. London: British Association of Sociab Workers, 1975.

(5) Bruckner J. Physical therapists as double agents. Ethica dilemmas of divided loyalties. Physical therapy 1987; 67. 3: 383-387.

(6) Code of ethics for the profession of dietetics. Fournal of the American Dietetics Association 1988; 88, 12: 15920 1596.

(7) Doyal L. A Phase II and III course in medical ethics an law. London Hospital Medical College, Bartholomew's Medical College, Queen Mary College Personal communication.

(8) Gillon R. Beneficence: doing good for others. British medical journal 1985; 291: 44-45.

(9) Gillon R. Justice and medical ethics. British medica journal 1985; 291: 201-202.

(10) Gillon R. Where respect for autonomy is not the answer British medical journal 1985; 292: 48-49.

(11) Gillon R. Confidentiality. British medical journal 1985 ; 291: 1634-1636. 